\title{
Release of Phospholipid Fatty Acid from Human Erythrocytes
}

\author{
STEPHEN B. SHOHET \\ From the Division of Hematology at the Children's Hospital Medical Center, \\ Boston, Massachusetts 02115
}

A в S T R A C T To study the catabolism of erythrocyte phospholipids, human erythrocytes were labeled with radioactive fatty acid (FA). Labeling was performed by the two separate routes which together are thought to be responsible for the majority of phosphatide renewal in the red cell: (a) passive equilibration of erythrocytes with preformed acid-labeled red cell phosphatidylcholine (PC) and (b) active, "acylase"-dependent, incorporation of free fatty acid in the presence of ATP coenzyme A and magnesium. (As measured here "acylase" $=$ the over-all effect of fatty acid thioesterification and the action of acyl-CoA : acylglycerophosphoryl acyltransferase.) The labeled cells were then reincubated in serum and the loss of radioactivity from cells into serum was examined.

The phosphatide fatty acid introduced by these two routes was incorporated into two distinct cellular phosphatide pools with little mixing. The fatty acid in passively introduced phosphatidyl choline was released primarily as the intact phosphatide, whereas actively incorporated PC fatty acid was released primarily as free FA. As expected for an exchange process, the passively introduced PC was released at the same rate as it was introduced. However, the actively incorporated FA was released from the cell at a slower rate than its incorporation into PC. This latter phenomenon was explained by the observation of transfer of PC fatty acid to phosphatidyl ethanolamine and "neutral lipid" before its release to serum. This transfer process was inhibited by previous heating of the reincubation serum.

The differences in the character of the released label, in the rate of release of the label, and in the influence of the reincubation serum all indicate separate pathways for the renewal of phosphatide introduced into red cells by these two routes.

Part of the material presented here has previously been published in abstract form (1969 J. Clin. Invest. 48: 77a).

Received for publication 25 December 1969 and in revised form 30 March 1970.

\section{INTRODUCTION}

The membrane phosphatides of mature human erythrocytes are continuously renewed during the circulation of the cell (1). Phosphatidyl choline (PC) and phosphatidyl ethanolamine ( $\mathrm{PE}$ ) which together comprise over $60 \%$ of the red cell membrane phospholipids are the molecular species which are primarily involved in this process. Since the red cell lacks acetyl Co-A carboxylase (2), this renewal occurs without the de novo synthesis of fatty acids. Two major pathways for this renewal have been demonstrated. The first involves a passive exchange of intact phosphatides (phosphoglyceride backbone plus fatty acids) between serum lipoproteins and red cell membranes $(3-6)$. The second involves an energy-dependent acylation within the membrane of either endogenous RBC or plasma lysophosphatides by free fatty acids derived from plasma (7-10).

The red cell does not increase its total content of phosphatide during its life-span. While it is clear that the first phosphatide renewal mechanism (exchange) would result in no net change in membrane phosphatide content, the second mechanism (acylation) would, in the absence of a parallel catabolic process, cause an increase in membrane phosphatide content. That such a catabolic process may exist is suggested by studies which have shown that the fatty acid moiety of red cell phosphatides may leave the cell independently of the phosphoglyceride backbone $(11,12)$.

To explore this catabolic process, the fate of red cell phospholipid fatty acids derived from passive exchange and active acylation was studied. These studies confirm that cell phosphatide derived by passive exchange is lost from the cell primarily by passive return of the complete molecule to the plasma. In contrast, they demonstrate that cell phosphatide derived by active acylation is in large part catabolized by an independent process involving the release of the phosphatide fatty acids alone to the plasma. They further indicate that the fatty acids incorporated by active acylation enter a pool of membrane phospholipids which is distinct from the pool 
derived from passive exchange. Moreover, the fatty acids in this "acylated" pool are transferred among lipid classes within the cell before their release into plasma.

\section{MATERIALS AND METHODS}

\section{A. Reagents}

Crystallized human serum albumin for the incorporation of labeled fatty acid was obtained from Dade Div., American Hospital Supply Corp., Miami, Fla. Linoleic acid-1 $-{ }^{14} \mathrm{C}$, palmitic acid-1 $-{ }^{14} \mathrm{C}$, and palmitic acid-9,10- ${ }^{3} \mathrm{H}$, were obtained from New England Nuclear, Boston, Mass. Nonradioactive phosphatidylcholine and phosphatidyl ethanolamine were obtained from Applied Science Labs, Inc., State College, $\mathrm{Pa}$. Alternatively, phosphatidyl choline was obtained from lipid extracts of human erythrocytes and purified by thin-layer chromatography (TLC) (13) on prepared silica gel plates (Brinkmann Instruments, Westbury, N. Y.). Defatted albumin for the removal of superficial red cell free fatty acid (10) was prepared from human fraction V generously supplied by the Massachusetts State Department of Health and defatted by activated charcoal equilibration as described by Chen (14). Phospholipase $\mathrm{A}_{2}$ from Crotalus terrificus terrificus venom was obtained from the Calbiochem, Los Angeles, Calif.

\section{B. Labeled phosphatides}

1. Phosphatidyl choline (PC) labeled primarily in the glycero-2 position was prepared from human erythrocyte phosphatidyl choline by conversion to lysophosphatidyl choline by the action of phospholipase $\mathrm{A}_{2}$ as described by Hanahan (15) ; this preparation was then reacylated with linoleic${ }_{1-14} \mathrm{C}$ fatty acid in the presence of coenzyme A, ATP, and glucose in Krebs-Hanseleit buffer (KHB) at $\mathrm{pH} 7.4$ following the method of Waite and van Deenen using fresh unwashed erythrocyte stroma as the enzyme source (16). Following the reacylation lipids were extracted by the method of Rose and Oklander (17) and purification of phosphatidyl choline was achieved by a minor modification of the method of Hanahan, Dittner, and Warashina (18). Subsequent hydrolysis of aliquots of this preparation with phospholipase $A_{2}$ showed that $93 \%$ of the label could be removed with this enzyme and, therefore, was in the 2 position.

2 . In the combined active and passive incorporation experiments which are discussed in section $\mathrm{C}-4, \mathrm{e}$ below, ${ }^{14} \mathrm{C}$ labeled "natural" erythrocyte PC was used for the passive label. This was obtained in advance by incubating human erythrocytes with palmitic acid- ${ }^{14} \mathrm{C}$, coenzyme $\mathrm{A}$, and ATP (16). The lipids were then extracted and purified as described above in section 1 . Subsequent hydrolysis of aliquots of the purified PC showed that $26 \%$ of the incorporated palmitic acid $-{ }^{14} \mathrm{C}$ label was in the 2 position. ${ }^{1}$

\section{Methods}

\section{Cell Collection and Preparation}

Peripheral venous blood was obtained from human donors and defibrinated at room temperature with glass beads. The

\footnotetext{
${ }^{1}$ In contrast to the rest of the experiments described here palmitic acid was used in the double label experiments. While we would have preferred to use linoleic acid because of more rapid active uptake and the known predilection of this FA for the 2 position of RBC phosphatides the only major FA of RBC phosphatides available with both ${ }^{14} \mathrm{C}$ and ${ }^{8} \mathrm{H}$ labels was palmitic acid.
}

red cells were separated from the serum and then from residual leukocytes and platelets with multiple washes in $\mathrm{KHB}$ at $\mathrm{pH} 7.4$ as previously described (10). When reconstituted to an hematocrit of $50 \%$, the white blood cell count of the red cell suspension was below 400 cells $/ \mathrm{mm}^{3}$.

\section{Lipid Analyses}

Erythrocyte lipids were extracted by Rose's method (17). The total lipid phosphorus of these extracts was determined from an aliquot by the method of Lowry, Roberts, Leiner, $\mathrm{Wu}$, and Farr (19). Major lipid components were then isolated by thin-layer chromatography using minor modification $^{2}$ of the method of Skipski, Peterson, and Barclay (13). The various lipid classes were located by iodine staining and identified by $R_{f}$ values and specific spot tests as previously described (10). Certain spots were then scraped from the plate and determination of lipid phosphorus and radioactivity were made on aliquots of sonicated suspensions of this material by the direct methods of Parker and Peterman (20) and Snyder and Stephens (21). Overall recovery of known quantities of labeled phosphatidyl choline and phosphatidyl ethanolamine was found to be greater than $95 \%$ for both lipid phosphorus and radioactivity by these methods.

In some cases, residual incubation sera were analyzed in a similar fashion: the serum was first recentrifuged at $4^{\circ} \mathrm{C}$ at $15,000 \mathrm{~g}$ for $\frac{1}{2} \mathrm{hr}$ in order to remove any contaminating cells or particles of "blood dust" $(22,23)$. Lipid extracts were then prepared (24) and silica gel thin-layer chromatography was performed on aliquots in order to separate both phospholipids and neutral lipids $(13,25)$. By following the recovery of known amounts of linoleic acid- ${ }^{14} \mathrm{C}$ labeled phosphatidyl choline and ${ }^{3} \mathrm{H}$-labeled palmitic acid added to blank serum samples, the over-all recovery of this extraction and chromatography was found to be $85 \%$ for phosphatidyl choline and $91 \%$ for free fatty acid. There was only minor transfer of fatty acid- ${ }^{-3} \mathrm{H}$ counts to the phosphatidyl choline spot (less than $2 \%$ ) or of phosphatidyl choline $-{ }^{14} \mathrm{C}$ counts to the free fatty acid spot (less than $5 \%$ ) during these blank procedures.

\section{Radioactivity Determinations}

Radioactivity measurements were made in a Packard TriCarb Model 3370 scintillation spectrometer. Buhler's solution (26) was used as the scintillation fluid. For experiments with doubly labeled erythrocytes, ${ }^{8} \mathrm{H}$ and ${ }^{14} \mathrm{C}$ counts were separated by the use of widely separated counting windows which were shown to produce less than $2 \%$ overlap in sensitivity of ${ }^{8} \mathrm{H}$ in the ${ }^{14} \mathrm{C}$ window. Known quantities of both isotopes were sequentially added to the counting vials as internal standards in order to correct for quenching and to calculate relative counting efficiency, and individual arithmetic corrections were made for the contamination of the ${ }^{3} \mathrm{H}$ counts by ${ }^{14} \mathrm{C}$ counts.

\section{Experimental Manipulations}

(a) Passive incorporation. Tracer amounts of phosphatidyl choline labeled with linoleic acid- ${ }^{14} \mathrm{C}$ were evaporated from chloroform to form a thin film on the bottom of $40-\mathrm{cc}$ round bottom centrifuge tubes. $3 \mathrm{cc}$ of autologous serum

${ }^{2} \mathrm{~A}$ solvent mixture of $250 \mathrm{cc} \mathrm{CHCl}_{3}, 150 \mathrm{cc} \mathrm{MEOH,} 30$ cc $\mathrm{HOAC}$, and $12 \mathrm{cc} \mathrm{H}_{2} \mathrm{O}$ was used to assure adequate separation of $\mathrm{NL}$ and $\mathrm{PE}$ respectively. Rechromatography of eluted spots of NL and PE produced single spots and single radioactive peaks. 
was added and the tubes were shaken until the PC was uniformly dispersed in the liquid phase. Glucose, ATP, coenzyme $\mathrm{A}$, and penicillin and streptomycin were then added. The final glucose concentration was $10 \mathrm{mmoles} / \mathrm{liter}$, the final ATP concentration was $1 \mathrm{mmole} / \mathrm{liter}$, and the final coenzyme A concentration was $0.1 \mathrm{mmole} / \mathrm{liter}$. The final penicillin and streptomycin concentrations were $50 \mu \mathrm{g} / \mathrm{cc}$. All incubations reported subsequently in these studies were done in the presence of the same additives. ${ }^{3}$ A washed red cell suspension in the same serum was then added to produce a final volume of $5 \mathrm{cc}$ and a final hematocrit of $10 \%$. Separate tubes were prepared in duplicate for each time sample studied.

The samples were then incubated for various times at $37^{\circ} \mathrm{C}$ with gentle agitation. After incubation, the cells were centrifuged to remove the media and then washed three times with $5 \mathrm{ml}$ of iced saline. Lipids of the media and the red cells were then extracted and analyzed as described above.

(b) Release from passively labeled pool. Red cells were prepared and incubated with phosphatidyl choline labeled with linoleic acid- ${ }^{14} \mathrm{C}$ as described in subsection $4 \mathrm{a}$ above. Following the saline washes, $5 \mathrm{cc}$ of fresh nonradioactive serum containing the previously noted additives were added and the cells were reincubated in stoppered flasks at $37^{\circ} \mathrm{C}$.

${ }^{3}$ Glucose, ATP, and coenzyme A were added during passive incorporation studies only to keep conditions analogous to the active incorporation studies. When these were omitted, no difference in incorporation of preformed PC was observed.
At each time period thereafter, the cells and serum were separated by centrifugation. The cells were then washed with saline. Lipid extracts were then prepared from both the cells and the serum and these were analyzed as described in Methods, sections 2 and 3.

(c) Active incorporation. $0.5 \mathrm{cc}$ of packed red cells was incubated in serum at an hematocrit of $10 \%$ with $2.0 \mu \mathrm{Ci}$ of linoleic acid-1 $1{ }^{14} \mathrm{C}$ bound to human serum albumin. Penicillin, streptomycin, glucose, ATP, and coenzyme A were added as previously described. Following incubation, the media were removed by centrifugation and the cells were washed three times with $5 \mathrm{cc}$ of iced saline. The cells were then washed four more times with 3-cc aliquots of an iced $1 \%$ solution of defatted human albumin in saline in order to remove surface FA. The lipids of the residual cells were then extracted, separated, and analyzed as in Methods, sections 2 and 3 .

(d) Release from actively labeled pool. Red cells were prepared and incubated with linoleic acid- ${ }^{14} \mathrm{C}$ as above. Following the saline and defatted albumin washes, the cells were resuspended in fresh autologous serum in order to reestablish a normal surface pool of nonradioactive fatty acids (10). After a $5 \mathrm{~min}$ incubation at $37^{\circ} \mathrm{C}$, this serum was removed. An additional $5 \mathrm{cc}$ of the same serum containing glucose and additives was added and the cells were reincubated in stoppered flasks at $37^{\circ} \mathrm{C}$. At each time period thereafter, the cells were centrifuged and washed and then analyzed as in Methods, sections 2 and 3. The separated serum was similarly analyzed.

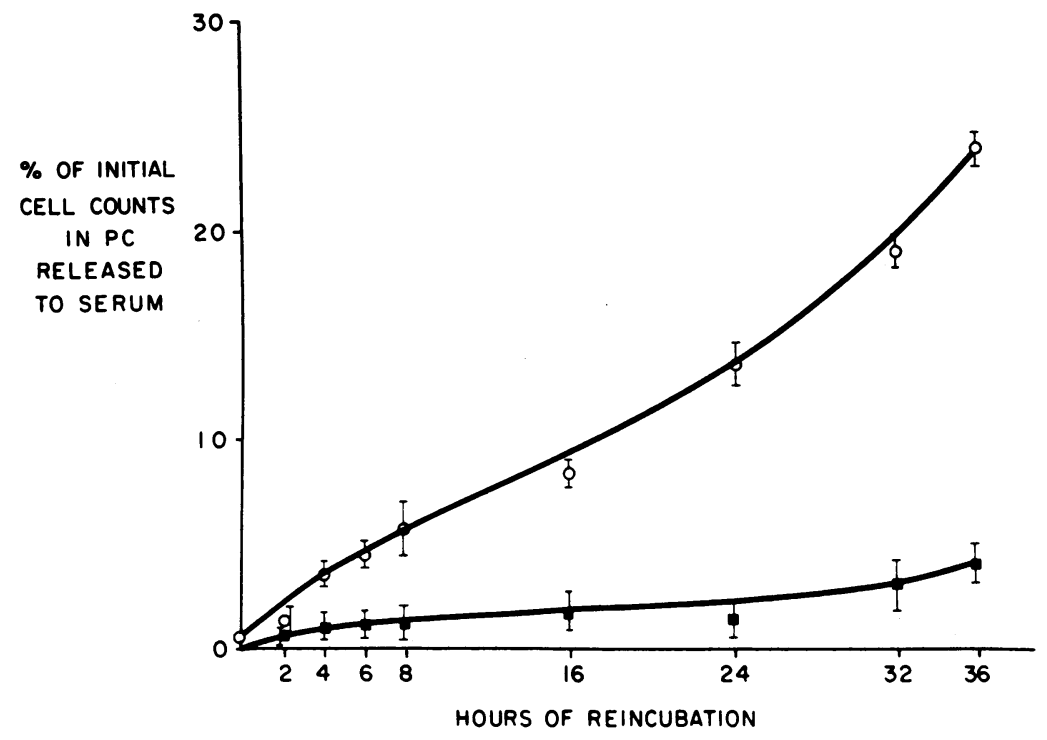

FIGURE 1 Disposition of radioactivity in serum lipids after reincubation of passively labeled cells. Cells were preincubated with preformed linoleic acid- ${ }^{14} \mathrm{C}-$ labeled phosphatidyl choline. They were then washed in saline and defatted albumin and reincubated in fresh autologous serum. The serum was extracted and lipids were isolated by TLC and counted. The radioactivity isolated is plotted as per cent of cell counts at zero time released to serum. $O=$ counts in serum PC; $\boldsymbol{\square}=$ counts in serum free fatty acid. No significant counts were detected in other serum components ( $<5 \%$ total counts). The points in this figure and in all subsequent figures represent averages of duplicates. The ranges are indicated by brackets. See Methods, sections $4 a$ and $b$ and Results, section A for further details. 


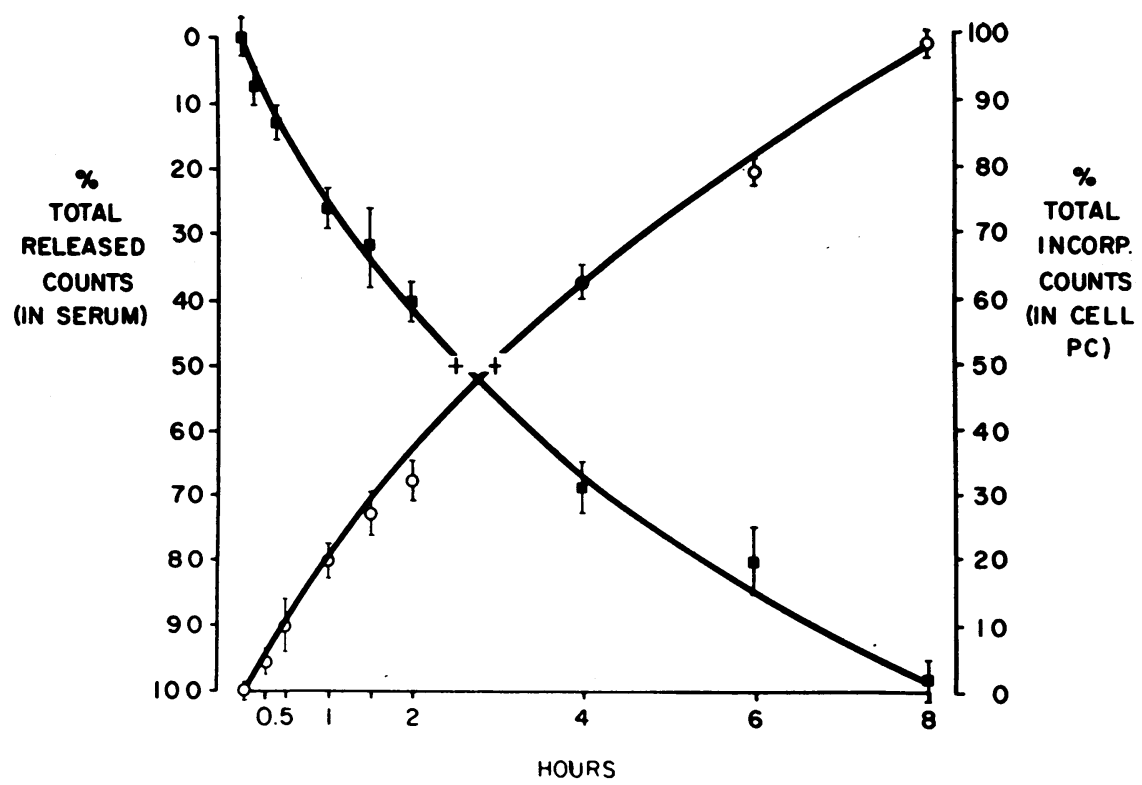

FIGURE 2 Comparative kinetics of passive incorporation of preformed phosphatidyl choline and subsequent release to serum. Cells were preincubated in serum with preformed linoleic acid- ${ }^{14} \mathrm{C}$-labeled $\mathrm{PC}$ for $8 \mathrm{hr}$. Aliquots were taken at various times and the cell lipids were extracted, analyzed, and counted. These results are indicated by the open circles $(O)$ and the right hand ordinate. The $8 \mathrm{hr}$ sample was indexed at $100 \%$ and the intermediate values are plotted as percentages of this value. After $8 \mathrm{hr}$, an aliquot of labeled cells was washed free of media and reincubated in fresh autologous serum. Aliquots of the reincubation serum were extracted and counted. These results are indicated by the closed squares ( $\square)$ and the left hand ordinate. The $8 \mathrm{hr}$ sample was indexed at $100 \%$ and the intermediate values are plotted as percentages of this value. $(+)=50 \%$ level of cumulated incorporation or release. See Methods, sections $4 \mathrm{a}$ and $\mathrm{b}$ and Results, section $\mathrm{B}$ for further details.

(e) Combined active and passive incorporation and subsequent release. In some experiments cells were preincubated to produce labeled phosphatides derived from both routes of incorporation as follows. Washed erythrocytes were incubated passively with preformed palmitic acid- ${ }^{14} \mathrm{C}$ labeled phosphatidyl choline for $12 \mathrm{hr}$. The labeled phosphatidyl choline used here was "natural" because it was derived from erythrocytes which had been previously incubated with palmitic acid ${ }^{14} \mathrm{C}$ as in Materials and Methods, section B-2. The cells were then washed three times with saline and incubated for $3 \mathrm{hr}$ in fresh serum containing palmitic acid- ${ }^{3} \mathrm{H}$. Following this second incubation, the cells were washed with saline and defatted albumin as previously described. At this stage, the ratio of ${ }^{3} \mathrm{H}$ counts to ${ }^{14} \mathrm{C}$ counts in extracted aliquots was approximately $3: 1 \quad\left({ }^{8} \mathrm{H} 34,000 \mathrm{cpm} / \mathrm{cc} \mathrm{RBC}\right.$; ${ }^{14} \mathrm{C} 11,000 \mathrm{cpm} / \mathrm{cc} \mathrm{RBC}$ ). The surface pool of free fatty acid was then reconstituted by a 5 min equilibration in autologous serum. This serum was removed, and the cells were finally reincubated in fresh serum at $37^{\circ} \mathrm{C}$. At various times, cell extracts and media counts were analyzed as in Methods, sections 2 and 3.

\section{RESULTS}

$A$. The nature of label release from passively labeled cells. The release to the serum of fatty acid- ${ }^{20} \mathrm{C}$-labeled PC which had been passively incorporated into erythro- cytes is shown in Fig. 1. There was only slight release of free fatty acid. Over $85 \%$ of the total counts eventually released to the serum were released as intact preformed phosphatides. Release of counts from cells proceeded continuously during the course of the experiment.

$B$. The comparative kinetics of passive incorporation and subsequent release of preformed linoleic acid $-{ }^{14} \mathrm{C}-$ labeled phosphatidyl choline. The time course of the passive incorporation of the radioactive counts into cells and their subsequent release from the cells into the reincubation serum in incubations with preformed phosphatidyl choline $-{ }^{14} \mathrm{C}$ is shown in Fig. 2. Expectedly, two virtually reciprocal curves were produced in these experiments. The $50 \%$ incorporation and release times for these two processes were similar. The half-times for the slopes of these curves were determined graphically and found to be $104 \mathrm{hr}$ for uptake $(0.66 \% / \mathrm{hr})$ and $95 \mathrm{hr}$ for release $(0.75 \% / \mathrm{hr})$.

C. Nature of label release from actively labeled cells. The release of fatty acid actively incorporated into erythrocyte lipids is shown in Fig. 3. In this experiment, in comparison to that shown in Fig. 1, the majority of 
counts actively incorporated into PC as linoleic acid was released as free linoleic acid. There was an increase in the rate of release of both types of counts towards the end of the experiment when slight hemolysis $(3 \%)$ was detectable. It should be emphasized that in these experiments, as well as in those shown in Fig. 1, defatted albumin washes were employed before reincubation. Such washes have previously been shown to remove a superficial red cell free fatty acid pool which is exchangeable with serum (8).

$D$. The comparative kinetics of active incorporation and subsequent release of $F A-{ }^{14} C$. The time course of the incorporation of radioactivity into cell phosphatidyl choline by the acylase-dependent pathway and its subsequent release is shown in Fig. 4 (Methods, section 4-d). Under these conditions, in comparison to those shown in Fig. 2, the two curves were not reciprocal. The $50 \%$ incorporation time was achieved considerably earlier than the $50 \%$ release time. The half-times for these two curves were determined graphically and found to provide an incorporation $\mathrm{t}$ of $48 \mathrm{hr}(1.4 \% / \mathrm{hr})$ and a release $\mathrm{t}$ of $178 \mathrm{hr}(0.38 \% / \mathrm{hr})$.

$E$. The release of radioactivity to serum from the same cells doubly labeled by both passive and active routes. In order to be certain that the differences in the rate of label release described above were due to differences in metabolic processing of the two types of incorporated phosphatidyl choline, rather than to differences in the in vitro procedures performed before reincubation, double label experiments of the type described in Methods, section 4-e were performed. In these studies, the passively incorporated phosphatidyl choline fatty acid was labeled with palmitic acid ${ }^{14} \mathrm{C}$ and the actively incorporated phosphatidyl choline fatty acid was labeled with palmitic acid- ${ }^{3} \mathrm{H}$. The results of such a reincubation are shown in Fig. 5 where it is seen that the release of passively incorporated counts into the incubation media was considerably faster than that of the actively incorporated counts. Similar results, not shown here, were obtained when the order of preincubations was reversed, i.e., free fatty $a{ }^{2} i d-{ }^{3} \mathrm{H}$ first and passive phosphatidyl choline ${ }^{-14} \mathrm{C}$ second.

$F$. The cellular disposition of linoleic acid- $-{ }^{14} \mathrm{C}$ incorporated into phosphatidyl choline by both active and passive routes. The data presented in Fig. 3 suggested an explanation for the difference in the rate of incorporation of counts into cells by the active route and their subsequent release to plasma. If removal of fatty acid from phosphatide backbone was required before release, the fatty acid might be reutilized within the cell and delayed release of fatty acid might be explained. To study such possible reutilization, the radioactivity within lipid classes isolated during reincubation in serum after both active and passive preincubations was estab-

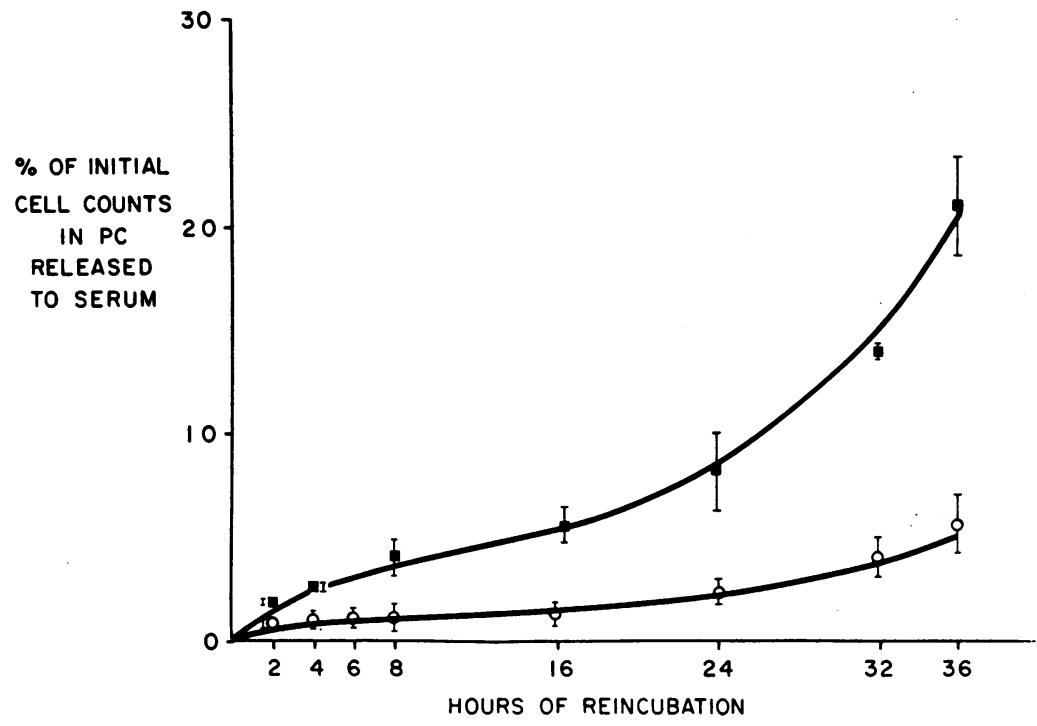

FIGURE 3 Disposition of radioactivity in serum lipids after reincubation of actively labeled cells. Cells were preincubated with linoleic acid- ${ }^{14} \mathrm{C}$ in serum. They were then washed with saline and defatted albumin and then reincubatd in fresh autologous serum. At various times the serum was extracted and lipids were isolated by TLC and counted. The radioactivity isolated is plotted as per cent of cell counts in PC at zero time released to serum. $O=$ counts in serum $\mathrm{PC} ; \boldsymbol{\square}=$ counts in serum free fatty acid. No significant counts were detected in other serum components ( $<5 \%$ total counts). See Methods, sections $4 \mathrm{c}$ and $\mathrm{d}$ and Results, section $\mathrm{C}$ for further details. 


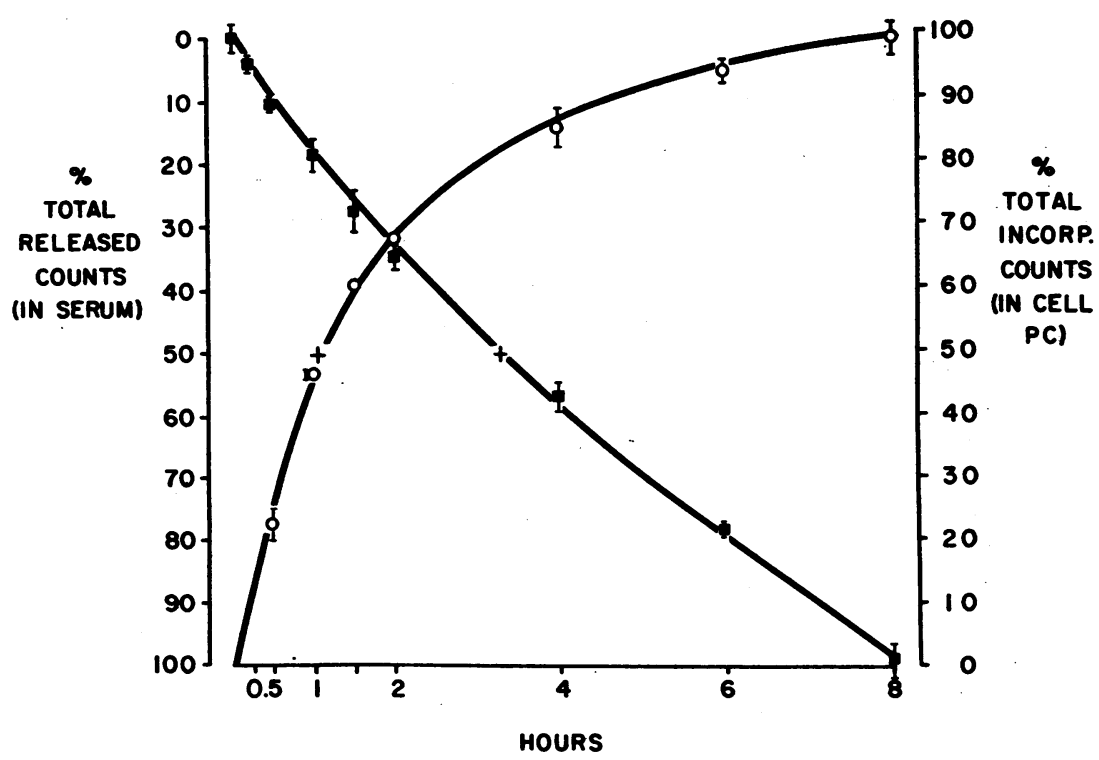

FIgURE 4 Comparative kinetics of active incorporation of FA into phosphatidyl choline and subsequent release to serum. Cells were preincubated with linoleic acid- ${ }^{14} \mathrm{C}$ in serum. During this incubation aliquots of cells were extracted and analyzed by TLC. Counts in PC are indicated by the right hand ordinate and the open circles (O). The $8 \mathrm{hr}$ sample is indexed at $100 \%$. Values are plotted as percentages of this value. After $8 \mathrm{hr}$ an aliquot of the labeled cells was washed with saline and defatted albumin and reincubated in fresh autologous serum. Aliquots of the reincubation serum were extracted and counted. These results are indicated by the left hand ordinate and the closed squares ( $\square$ ). The $8 \mathrm{hr}$ sample was indexed at $100 \%$ and intermediate values are plotted as percentages of this value. $(+)=50 \%$ level of cumulated incorporation or release. See Methods, sections $4 c$ and $d$ and Results, section $D$ for further details.

lished. In Fig. $6 \mathrm{~A}$ the effect of reincubation of actively labeled cells in fresh serum is shown. As PC counts fell, $\mathrm{PE}$ counts rose and then began to fall. Cell "neutral lipid" counts " slowly rose during this period. These effects were muted when the reincubation was performed in heated serum (Fig. 6 B). In both of these experiments, more than $90 \%$ of total cell radioactivity was present in PC, PE, and NL throughout the incubations and total recovery of radioactivity in serum and cells during incubation was greater than $95 \%$. Fig. $6 \mathrm{C}$ reveals that passively incorporated counts were found in phosphatidyl choline throughout. In these latter experiments, no significant counts were found at any time in phosphatidyl ethanolamine or "neutral lipids" and, as would be expected, there was no difference in cellular lipid distribution when heated serum was used for the

"This so-called "neutral lipid" (NL) in this chromatographic system is composed of several lipid entities. NL radioactivity in representative samples subjected to rechromatography in two separate systems $(27,28)$ was found in four major chromatography zone as follows: (a) cardiolipin-phosphatidic acid zone, 45\%; (b) free fatty acid zone, $40 \% ;(c)$ triglyceride zone, $10 \%$; and $(d)$ diglyceride zone, $5 \%$. reincubation. There was virtually no change in the rate of release of passively incorporated counts when heated serum was used (Fig. $6 \mathrm{D}$ ). In all of these studies, the total phosphorus and the distribution of major lipid classes was unchanged during the duration of the reincubation.

In further experiments, not shown here, the addition of excess nonradioactive PC to the incubation media in the passively labeled cells produced a major increase in the rate of loss of cell phosphatidyl choline label with either heated or unheated serum. There was little or no increase in the rate of phosphatidyl choline loss from actively labeled cells in either sera.

\section{DISCUSSION}

Previous data from others $(6,8)$ and data from corollary experiments from our laboratory (30) have indicated that the vast majority of phospholipid renewal in erythrocyte membrane occurs through two pathways: (a) the active acylation of lysophosphatides and (b) the passive exchange of preformed phosphatides. Incorporation of glycerides, glycerol, inorganic phosphorus, or cytidine diphosphate compounds were all minor in 
comparison to these two major incorporation routes (29, 30 ). In other studies we have shown that for the active pathway the delivery of fatty acid from the plasma to the lysophosphatide acceptors within the cell proceeds through two discrete precursor pools (10). Approximations of the magnitude of the active incorporation of fatty acids into phosphatide were made from measurements of the specific activities of these pools and compared to independent determinations of the magnitude of passive exchange of preformed phosphatides (6). The rates of red cell membrane phospholipid fatty acid renewal by both the active and passive routes were found to be approximately equal.

The dynamics and constitution of membrane lipids depend upon the balance of both incorporation and outflow pathways. Our previous studies examined some of the incorporation pathways for erythrocyte phosphatide fatty acids (10). The present experiments examined the outflow and eventual disposition of erythrocyte phosphatide fatty acids.

The methods used here are generally similar to those previously reported (10). It should be stressed, however, that in these studies all incubations were done in the presence of glucose, ATP, coenzyme A, and serum. The additives provided optimal conditions for energydependent pathways and the serum provided acceptor sites for exchange and release pathways. In the course of these studies we found that the addition of ATP and coenzyme A made very little difference in the extent of acylation in fresh cells $(<10 \%)$ but that these additions reduced the variation obtained when using cells which had been washed several times or which had been subjected to long preincubations.

We found two compartments of phosphatidyl choline in the red cell membrane. One of these was derived from passive exchange of red cell $\mathrm{PC}$ with serum $\mathrm{PC}$, while the other was derived from active incorporation of fatty acid into red cell membrane PC. Intact passively accumulated $\mathrm{PC}$ was released by the red cell into serum at the same rate that it was incorporated (Fig. 2), whereas actively incorporated PC fatty acid was released from the cell at a rate slower than its rate of incorporation into cell PC (Fig. 4). An alteration in the rate of release of the actively incorporated fatty acid radioactivity from the cell was not entirely unexpected since the radioactive fatty acid was distributed among

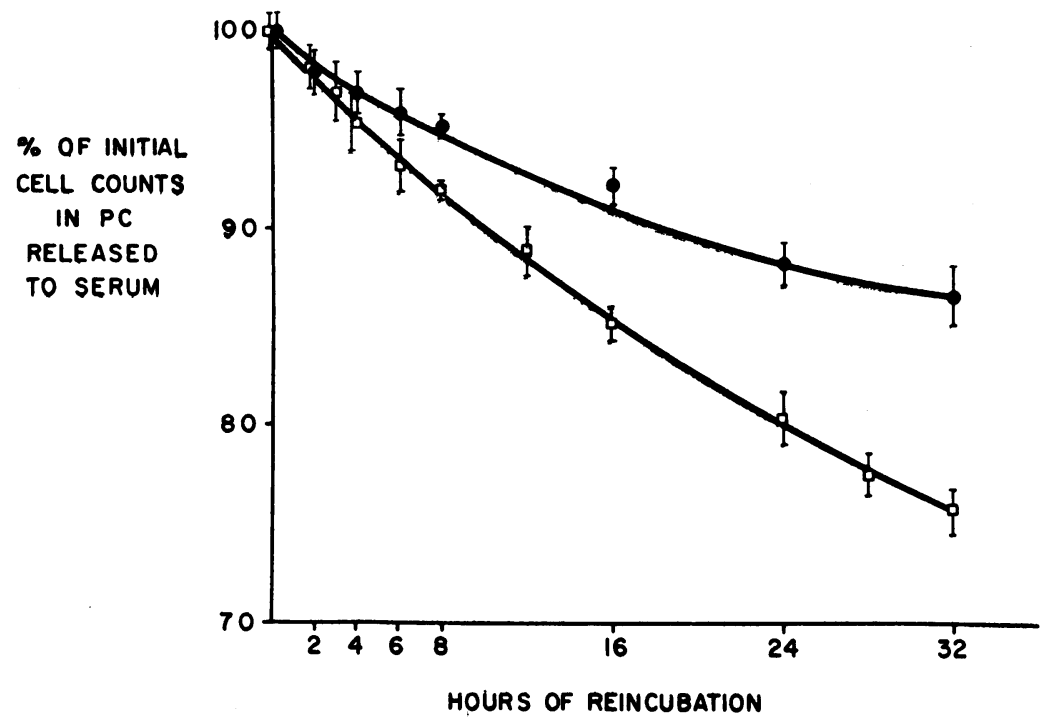

FigURE 5 Kinetics of loss of phosphatidyl choline FA from cells both actively and passively labeled. Cells were passively labeled with preformed natural erythrocyte $P C$ labeled with palmitic acid- ${ }^{14} \mathrm{C}$ (Methods, section $\mathrm{Bb}$ and $4 \mathrm{a}$ ). They were then actively relabeled with palmitic acid- ${ }^{8} \mathrm{H}$ (Methods, section $4 \mathrm{c}$ ). They were then washed in saline and defatted albumin to remove media and surface pools of free fatty acid and reincubated in fresh serum (Methods, section 4e). The serum was then extracted and counted for both isotopes (Methods, section 3), as was an aliquot of the original red cells. The cumulated serum counts were then subtracted from the original cell PC counts to derive the decline in cell counts. This is presented as the per cent drop in counts present in cell $\mathrm{PC}$ at zero time for each isotope. The closed circles $(\bullet)=$ the results obtained from the ${ }^{8} \mathrm{H}$ (active) label and the open squares $(\square)=$ the results obtained from the ${ }^{14} \mathrm{C}$ (passive) label. 

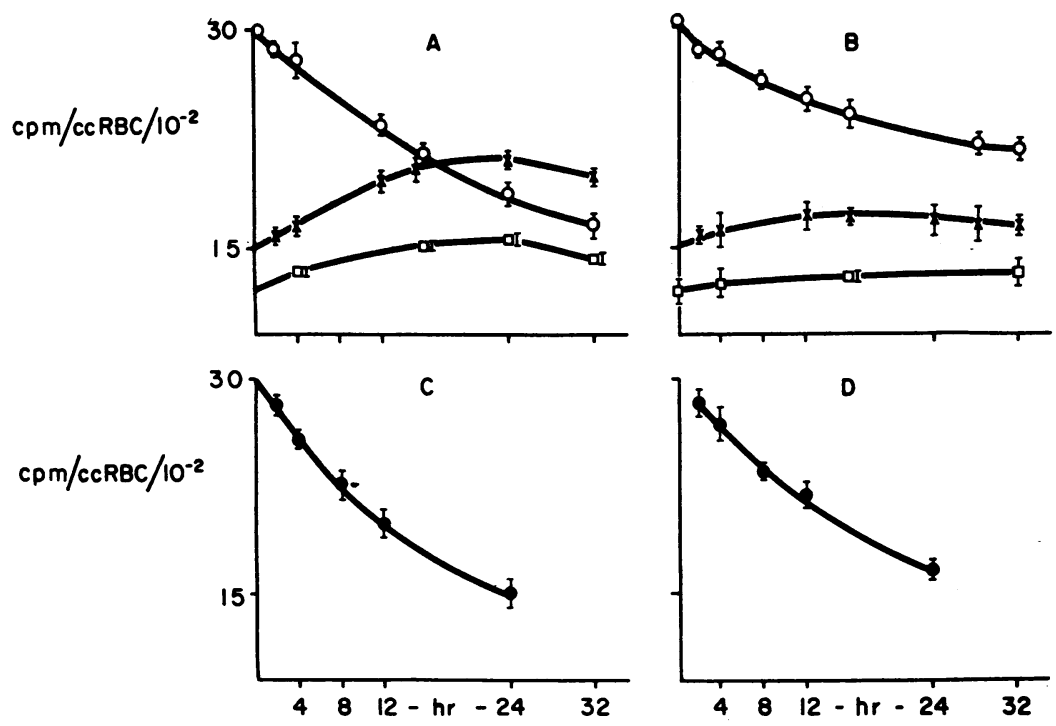

FIGURE 6 Distribution of cellular radioactivity during reincubation after active or passive labeling. For active labeling, cells were briefly incubated $\left(\frac{1}{2} \mathrm{hr}\right)$ with linoleic acid- ${ }^{14} \mathrm{C}$ in buffer in order to label phosphatidyl choline and to a lesser extent phosphatidyl ethanolamine and neutral lipids. They were then washed with saline and defatted albumin to remove the surface pool of free fatty acid. A normal surface pool was then established by a brief equilibration with serum. For the passively labeled studies, cells were incubated with high specific activity preformed phosphatidyl choline in serum for $3 \mathrm{hr}$. After the labeling, cells were reincubated in fresh or previously heated serum $\left(56^{\circ} \mathrm{C}, \frac{1}{2} \mathrm{hr}\right)$. Lipid extracts of the cells were prepared and total lipid phosphorus was determined. Lipids were then analyzed by TLC and specific activities of individual lipid classes determined. There was no significant loss of lipid $P$ in any of the reincubation samples or change in the per cent distribution of the major lipid classes during the reincubations. More than $90 \%$ of total label was contained in $\mathrm{PC}, \mathrm{PE}$, and NL. Total radioactivity recovery during the incubations was greater than $95 \%$. All data in Figs. $6 \mathrm{~A}-\mathrm{D}$ were obtained in experiments using the same cells and the same sera at the same time. See Methods, section F. $O=$ counts in PC; $X=$ counts in PE; $\square=$ counts in NL; $A=$ active incorporation, reincubation in fresh serum; $B=$ active incorporation, reincubation in heated serum; $C=$ passive incorporation, reincubation in fresh serum; $D=$ passive incorporation, reincubation in heated serum.

several classes of lipids in addition to PC. The fact that the rate of release from cells was slower than the rate of incorporation into PC suggested, among several possibilities, that this pool of PC fatty acid radioactivity might empty into other pools where dilution could occur before its eventual return to serum. Direct evidence for such a movement of fatty acid within cellular lipids was gained from the experiments presented in Fig. $6 \mathrm{~A}$ and will be discussed further below.

The data in Figs. 1 and 3 which show that the label released from actively labeled phosphatidyl choline was primarily free fatty acid whereas that released from passively labeled cells was primarily intact phosphatide supports the concept of a distinct metabolic fate for these two pools and indicates that there was only moderate mixing between them within the cells.
The data in the double label experiment shown in Fig. 5 confirms that passively incorporated preformed phosphatidyl choline fatty acid has a metabolic fate distinct from actively incorporated phosphatidyl choline fatty acid. The same cells were labeled by both active and passive processes which eliminated the possibility that artifacts of experimental manipulation were responsible for the different results. It should be emphasized that both labeling procedures produced the same species of phosphatidyl choline: the PC utilized for passive labeling had been prepared previously in red cells under conditions identical with those used in final active labeling; likewise, the same fatty acid was used for both procedures to eliminate any positional differences within PL due to differences in fatty acid species. Hence, for both active and passive incorporation, natural erythro- 
cyte PC was produced which differed only in the isotope label on the fatty acid.

The independence of the actively and passively established pools of phosphatidyl choline fatty acid is further emphasized in Fig. $6 \mathrm{~B}$ and D. Here it is apparent that heat treatment of the serum had little or no effect on the release of passively labeled phosphatidyl choline whereas it clearly influenced the actively incorporated label. It is also noteworthy that no phosphatidyl choline counts were converted into phosphatidyl ethanolamine or "neutral lipid" during the course of the passive reincubation.

The finding of a distinction between these two pools of cellular phosphatidyl choline is in agreement with the previous observations of Rowe (3) who found evidence for both an easily exchangeable and a more fixed phosphatide pool in red cell membranes, and with Reed (5) who has shown using a ${ }^{82} \mathrm{P}$ label that only a portion of cell phosphatidyl choline appears to be in equilibrium with serum phosphatidyl choline.

A dynamic movement of actively incorporated fatty acid between the cellular phospholipids is shown in Fig. $6 \mathrm{~A}$. Here it can be seen that the radioactivity in cellular phosphatidyl ethanolamine fatty acid and, to a less extent, in cellular "neutral lipid" fatty acid continued to rise while phosphatidyl choline radioactivity fell following reincubation of labeled cells in fresh nonradioactive serum. Direct precursor-product relationships between phosphatidyl choline fatty acid and either of the latter labeled pools cannot be assumed since all of the compounds were labeled to a variable extent initially and since all possible sources for ingress of fatty acid into phosphatidyl ethanolamine and "neutral lipid" from the reincubation serum are not known. However, it is reasonable to postulate that considerable fatty acid did transfer from phosphatidyl choline to phosphatidyl ethanolamine and perhaps to neutral lipids before final release to the serum since, with no change in the per cent distribution of lipids, phosphatidyl ethanolamine and "neutral lipid" radioactivity rose and then fell while the phosphatidyl choline radioactivity continuously fell and serum radioactivity continuously rose. Furthermore, at any time period virtually all of the loss of PC counts can be accounted for by the combined net rise in $\mathrm{PE}$, NL, and serum counts. Hence, at least some of the fatty acid released to the serum appears to have passed through phosphatidyl ethanolamine and a "neutral lipid" pool. With regard to the mechanism of this fatty acid transfer we have conducted other experiments in similar reincubations to rule out specious apparent transfer due to conversion of labeled PC to PE by base-exchange or demethylation. These experiments, which will be presented elsewhere, indicate that neither of these possi-

Shohet, S. B. 1970. The mechanism of an apparent transfer of fatty acid from phosphatidyl choline to phosphatidyl

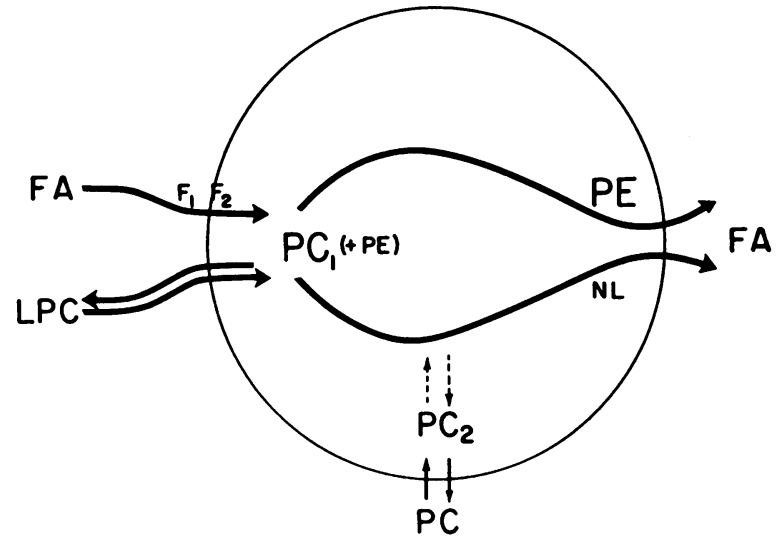

FIGURE 7 Working scheme of phospholipid metabolism in the mature human erythrocyte. FA = free fatty acid bound to serum albumin; $\mathrm{LPC}=$ lysophosphatidyl choline; $\mathrm{F}_{1}=$ albumin extractable free fatty acid; $F_{2}=$ albumin nonextractable neutral lipid; $\mathrm{PC}_{1}=$ phosphatidyl choline - actively established pool; $\mathrm{PC}_{2}=$ phosphatidyl choline - passively established pool; $\mathrm{PE}=$ phosphatidyl ethanolamine; $\mathrm{NL}=$ "neutral lipids."

bilities occur and that the phenomenon observed is indeed the transfer of fatty acid amongst phosphatide classes. It is of interest that this apparent "transferase" activity is partially dependent upon the presence of fresh serum. The "transferase" activity may be present in a heat-labile serum factor or may be a membrane-bound activity which is dependent upon labile serum cofactors. In this regard it should be mentioned that Vogel and Bierman have observed phospholipase activity in post heparin human plasma (31).

Finally, it should be emphasized that although a flux of fatty acid through RBC phosphatides has been observed here, a classical "phospholipase" activity in red cells has not been defined by these experiments. We have not been able to passively add specific exogenous phosphatide to red cells and then detect the release of its fatty acid or increases in lysophosphatide. Other laboratories have repeatedly looked for such an effect $(7,8,32,33)$. With the notable exception of the demonstration of a phospholipase for phosphatidyl glycerol (33), no specific phospholipases have been found. The presence of this phosphatide has not yet been established in human erythrocytes although diphosphatidyl glycerol probably is present in small amounts (34). It is an intriguing possibility that the transfer reactions we have described here may be passing fatty acid on to a final acceptor which is accessible to attack by a phospholipase but we have no evidence for this at present. It is also possible that only endogenous, actively assembled mem-

ethanolamine in human erythrocytes. Submitted for publication. 
brane phosphatide is situated within the membrane in a position susceptible to either such internal transferase reactions or to external serum phospholipase attack.

A schematic summary of a working interpretation of our results is shown in Fig. 7. In the horizontal series of steps, a distinct cellular pool of phospholipid $\left(\mathrm{PC}_{1}+\right.$ $\mathrm{PE}$ ) is assembled by an ATP-dependent acylation of lysophosphatide and fatty acid. The fatty acid is delivered to the acylation site from serum through a series of discrete stages $\left(F_{1}+F_{2}\right)$ which have been previously described (10). The predominent phospholipid found at this state is PC though PE is also formed. The fatty acid moiety of the actively produced phosphatidyl choline $\left(P C_{1}\right)$ can then be removed and transferred to other cellular acceptors to produce additional phosphatidyl ethanolamine and "neutral lipids." This "transferase" activity is apparently facilitated by the presence of unheated autologous serum. Part of the final return of fatty acid back to serum is derived from these secondary acceptors.

As shown by the vertical arrows, there is also a passive equilibration of serum phosphatidyl choline with another cellular pool of phosphatidyl choline $\left(\mathrm{PC}_{2}\right)$. During catabolism, there is only slight mixing between the actively and passively established pools of phosphatidyl choline and the phosphatidyl choline introduced into each can be distinguished by its subsequent metabolic behavior.

\section{ACKNOWLEDGMENTS}

I am grateful to Doctors David G. Nathan and Manfred L. Karnovsky of the Departments of Pediatrics and Biological Chemistry at the Harvard Medical School for continuing suggestions and interpretations during the execution of this work. I am also glad to acknowledge the careful attention of Mrs. E. Haddad in the preparation of this manuscript.

This study was supported by U. S. Public Health Service Grant HD 02777 and by a grant from the Medical Foundation of Boston, Inc., Boston, Mass.

\section{REFERENCES}

1. Farquhar, J. W., and E. H. Ahrens, Jr. 1963. Effects of dietary fats on human erythrocyte fatty acid patterns. J. Clin. Invest. 42: 675.

2. Pittman, J. G., and D. B. Martin. 1966. Fatty acid biosynthesis in human erythrocytes: evidence in mature erythrocytes for an incomplete long-chain fatty acid synthesizing system. J. Clin. Invest. 45: 165.

3. Rowe, C. E. 1960. The phospholipids of human-blood plasma and their exchange with the cells. Biochem. J. 76: 471 .

4. Reed, C. F. 1959. Studies of in vivo and in vitro exchange of erythrocyte and plasma phospholipids. J. Clin. Invest. 38: 1032. (Abstr.)

5. Reed, C. F. 1968. Phospholipid exchange between plasma and erythrocytes in man and the dog. J. Clin. Invest. $47: 749$.
6. Tarlov, A. R. 1966. Lecithin and lysolecithin metabolism in rat erythrocyte membranes. Blood. 28: 990. (Abstr.)

7. Oliveira, M. M., and M. Vaughan. 1964. Incorporation of fatty acids into phospholipids of erythrocyte membranes. J. Lipid Res. 5: 156.

8. Mulder, E., J. W. O. VanDenBerg, and L. L. M. van Deenen. 1965. Metabolism of red cell lipids. II. Conversions of lysophosphoglycerides. Biochim. Biophys. Acta. 106: 118.

9. Donabedian, R. K., and A. Karmen. 1967. Fatty acid transport and incorporation into human erythrocytes in vitro. J. Clin. Invest. 46: 1017.

10. Shohet, S. B., D. G. Nathan, and M. L. Karnovsky; 1968. Stages in the incorporation of fatty acids into red blood cells. J. Clin. Invest. 47: 1096.

11. Fischer, H., E. Ferber, I. Haupt, A. Kohlschütter, M. Modolell, P. G. Munder, and R. Sonak. 1967. Lysophosphatides and cell membranes. Protides Biol. Fluids. Proc. Colloq. Bruges. 15: 175.

12. Munder, P. G., E. Ferber, and H. Fischer. 1965. Untersuchungen über die Abhängigkeit der cytolytischen Wirkung des Lysolecithins von Membranenzymen. $Z$. Naturforsch. 20: 1048.

13. Skipski, C. P., R. F. Peterson, and M. Barclay. 1964. Quantitative analysis of phospholipids by thin layer chromatography. Biochem. J. $90: 374$.

14. Chen, R. F. 1967. Removal of fatty acids from serum albumin by charcoal treatment. J. Biol. Chem. 242: 173.

15. Hanahan, D. J. 1952. The enzymatic degradation of phosphatidyl choline in diethyl ether. J. Biol. Chem. 195: 199.

16. Waite, M., and L. L. M. van Deenen. 1967. Hydrolysis of phospholipids and glycerides by rat liver preparations. Biochim. Biophys. Acta. 137: 498.

17. Rose, H. G., and M. Oklander. 1965. Improved procedure for the extraction of lipids from human erythrocytes. J. Lipid Res. 6: 428.

18. Hanahan, D. J., J. C. Dittmer, and E. Warashina. 1957. A column chromatographic separation of classes of phospholipids. J. Biol. Chem. 228: 685.

19. Lowry, O. H., N. R. Roberts, K. Y. Leiner, M. L. Wu, and A. L. Farr. 1954. The quantitative histochemistry of brain. I. Chemical methods. J. Biol. Chem. 207: 1.

20. Parker, F., and N. F. Peterson. 1967. Quantitative analysis of phospholipids and phospholipid fatty acids from silica gel thin-layer chromatograms. J. Lipid Res. 6: 455.

21. Snyder, F., and N. Stephens. 1962. Quantitative carbon14 and tritium assay of thin-layer chromatography plates. Anal. Biochem. 4: 128.

22. Weed, R. I., and C. F. Reed. 1966. Membrane alterations leading to red cell destruction. Amer. J. Med. 41: 681.

23. Weed, R. I., and C. F. Reed. 1965. The relation of erythrocyte fragmentation to cellular destruction. Blood. 26: 894 (Abstr.).

24. Folch, J., M. Lees, and G. H. Sloane Stanley. 1957. A simple method for the isolation and purification of total lipids from animal tissues. J. Biol. Chem. 226: 497.

25. Gottfried, E. L. 1967. Lipids of human leukocytes: relation to cell type. J. Lipid Res. 8: 321.

26. Buhler, D. R. 1962. A simple scintillation counting technique for assaying $\mathrm{C}^{14} \mathrm{O}_{2}$ in a Warbug flask. Anal. Biochem. 4: 413 . 
27. Deykin, D., and R. K. Desser. 1968. The incorporation of acetate and palmitate into lipids by human platelets. J. Clin. Invest. $47: 1590$.

28. Skipski, V. P., J. J. Good, M. Barclay, and R. B. Reggio. 1968. Quantitative analysis of simple lipid classes by thin layer chromatography. Biochim. Biophys. Acta. 152: 10.

29. Reed, C. F. 1968. Incorporation of orthophosphate $-{ }^{32} \mathrm{P}$ into erythrocyte phospholipids in normal subjects and in patients with hereditary spherocytosis. J. Clin. Invest. 47: 2630 .

30. Shohet, S. B., and D. G. Nathan. 1970. Incorporation of phosphatide precursors from serum into erythrocytes. Biochim. Biophys. Acta. 202: 202.
31. Vogel, W. C., and E. L. Bierman. 1967. Post heparin lecithinase in man and its positional specificity. J. Lipid Res. 8: 46.

32. Robertson, A. F., and W. E. M. Lands. 1964. Metabolism of phospholipids in normal and spherocytic human erythrocytes. J. Lipid Res. 5: 88.

33. Paysant, M., D. Delbauffe, R. Wald, and J. Polonovski. 1967. Action enzymatique des globules rouges de rat sur le phosphatidylglycérol. Bull. Soc. Chim. Biol. 49: 169.

34. Dodge, J. T., and G. B. Phillips. 1967. Composition of phospholipids and of phospholipid fatty acids and aldehydes in human red cells. J. Lipid Res. 8: 667. 